\title{
Predicting Microstructural Transitions via Computer Modeling and the Importance of Strain and Temperature in IN718 Forging Design
}

\author{
Andrew Haynes ${ }^{1}$, Tim Howson ${ }^{2}$ \\ ${ }^{1}$ Pratt \& Whitney; 400 Main Street; East Hartford, CT 06108 \\ ${ }^{2}$ Wyman-Gordon Forgings; 244 Worcester Street; North Grafton, MA 01536-8001
}

\begin{abstract}
Press forged IN718 is widely used for high strength gas turbine engine disks. Meeting yield strength requirements with statistical process capability is important for these high strength applications and that capability depends on the microstructure of the material, with subtle microstructural differences having an effect on yield strength. The differences in microstructure within a forging can be related back to the strain and temperature history of any one area, which can now be readily simulated with computer software. Linking the capability of the computer simulation software, microstructure and tensile properties to design in process capability has been the goal of forgers, researchers and OEM users of IN718 for the last decade. While generic rules of thumb and historical experience is sufficient for forging design in most cases, emphasis on weight reduction and process capability from the very first part, has increased the need for greater precision in forging design requirements. Additionally the relationship between strain and temperature in the development of a forging microstructure can be manipulated in forging design, if material models are further developed. Analysis of $1200 \backslash 176 ; \mathrm{F}$ tensile strength from solution treated and aged IN718 forgings as well as microstructure and the results of forging simulations were combined to regress a simple formula that would predict transitions in the microstructure that were associated with tensile scatter. This model was then modified into a design criteria that was applied to forging simulations for both validation and modification of forging designs.
\end{abstract}

